SCIDice
International Journal of Dentistry and Oral Science (IJDOS)

ISSN: $2377-8075$

\section{Cleidocranial Dysostosis - A Case Report}

Abarna Jawahar ${ }^{1}$, G. Maragathavalli $i^{*}$

${ }^{1}$ Postgraduate Student, Department of Oral Medicine and Radiology, Saveetha Dental College and Hospitals, Saveetha Institute of Medical and Technical Sciences (SIMATS), Chennai-600077, India.

${ }^{2}$ Professor, Department of Oral Medicine and Radiology, Saveetha Dental College and Hospitals, Saveetha Institute of Medical and Technical Sciences (SIMATS), Chennai-600077, India.

\title{
Abstract
}

Cleidocranial dysplasia (CCD) is a rare autosomal dominant disorder that exhibits several skeletaldefects and dental abnormalities.The characteristic features seen in cleidocranial dysplasia are aplastic or hypoplastic clavicles,delayedclosureor open fontanelles, open skull sutures and dental abnormalities, which includes over retention of primary dentition and delayed eruption of permanent dentition, with presence of multiple impacted supernumerary teeth. In this article we report 2 cases of cleidocranial dysplasia reported in our dental outpatient department with an aim to highlight the clinical features,dental abnormalities and radiological features.

Keywords: Cleidocranial Dysostosis; Cleidocranial Dysplasia; Impacted Permanent Teeth; Autosomal Dominant.

\section{Introduction}

Cleidocranial dysplasia is a rare congenital defect affecting the bones which undergo intramembranous ossification primarily. The bones usually involved are skull,clavicles and jaws [1, 2].Cleidocranial dysplasia is rare in occurrence with an incidence of 1:10,00,000 individual and has an autosomal dominant inheritance pattern [3-5]. It was first described by Pierre Marie and Paul Sainton in the year 1898,subsequently more than 1000 cases have been documented in the medical literature $[6,7]$. Cleidocranial dysplasia is also known as mutational dysostosis,cleidocranial dysostosis and Marie and Sainton disease [8].

Individuals affected with CCD exhibit multiple skeletal defects, with striking characteristic features of partial or complete absence of clavicles, delayed closure of the fontanelles,presence of open skull sutures, wide pubic symphysis and multiple wormian bones [9]. Typically, the clavicles are underdeveloped in varying degrees resulting in excessive mobility allowing them to approximate the shoulders anteriorly [10]. Delayed closure of fontanelles and presence of metopic sutures result in frontal bossing.
Patients with CCD usually exhibit short stature, hypertelorism, depressed nasal bridge, maxillary hypoplasia and multiple dental abnormalities. The thoracic cage is small and bell shaped. The clinical and dental features of CCD are unique and may lead to initial diagnosis in most cases [11-13].

The classic dental features seen in CCD includes retention of the primary dentition, delayed eruption with consequent impaction of the permanent teeth and presence of multiple impacted supernumerary teeth, crown and root abnormalities [14-20].

Successful dental treatment of CCD requires a compliant patient and an interdisciplinary team approach involving orthodontics,prosthodontic and maxillofacial surgeon.Since early diagnosis of CCD is essential for initiating the appropriate treatment approach,the clinicians should be aware of the characteristic features.Hence the aim of the article is to describe the clinical features,dental abnormalities and radiological features of two cases of cleidocranial dysplasia reported in our dental outpatient department.

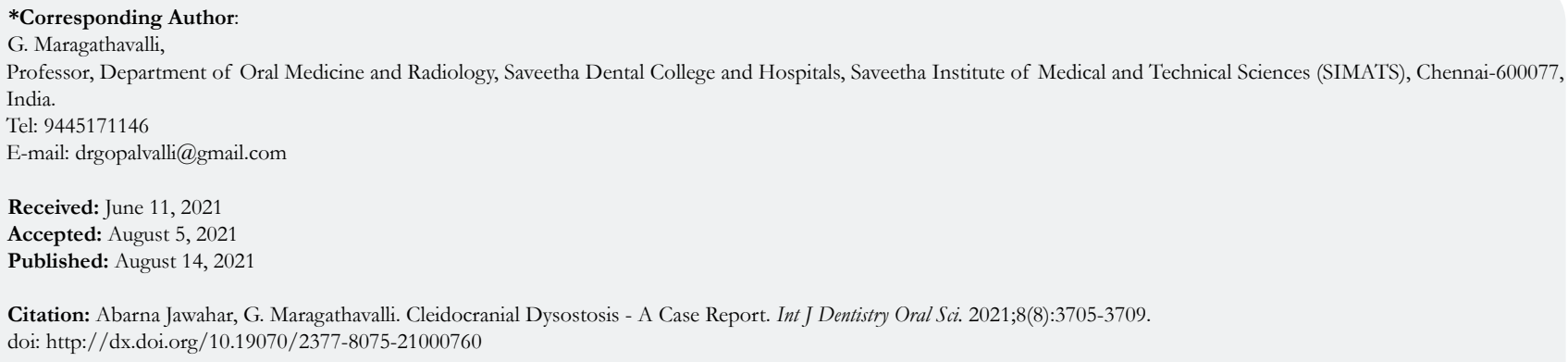

Copyright: G. Maragathavalli 2021 . This is an open-access article distributed under the terms of the Creative Commons Attribution License, which permits unrestricted use, distribution and reproduction in any medium, provided the original author and source are credited. 


\section{Case Description}

\section{Case 1}

A 25-year-old male reported to the department of Oral Medicine and Radiology with a complaint of multiple missing teeth in the upper front teeth region for the past 8 years and wanted replacement. His past dental history revealed that he had undergone restoration in a private dental clinic 5 years before and no dental extractions done previously. His past medical history and family history were non-contributory.

On general examination the patient was apparently well with moderately built and short in stature. On physical examination the patient was able to approximate the shoulders anteriorly demonstrating the hypermobility of the joint (Figure Ia). On extraoral examination the patient had frontal bossing,hypertelorism, depressed nasal bridge and hypoplastic maxilla leading to relative prognathic mandible (Figure Ib \& Ic). Intraoral examination revealed narrow high arched palate,multiple over-retained deciduous teeth with multiple unerupted permanent teeth(Figure IIa \&IIb). Based on the clinical and intra-oral features a provisional diagnosis of cleidocranial dysplasia was given.

The patient was advised to undergo panoramic imaging,posterioanterior skull view and posterio-anterior chest view for further evaluation. Panoramic imaging (Figure IIIa) revealed the presence of a total 56 teeth including multiple impacted permanent and supernumerary teeth distributed along the entire region of maxillary and mandibular alveolar bone.Posterio-anterior skull view (Figure IIIb) revealed brachycephaly withpresence of wormian bones,open fontanelles, thickened calvarium and poorly developed sinuses. The posterio-anterior view of the chest (Figure IIIc) revealed bell shaped rib cage and complete absence of the clavicle on both the sides.

Based on the clinical,extraoral,intraoral and radiographic features a final diagnosis of cleidocranial dysplasia was given.The patient is currently being treated by a team comprising of oral and maxillofacial surgeon,orthodontist and prosthodontist, planned for orthognathic surgery to correct the malocclusion and surgical removal of impacted teeth to be followed by replacement of missing teeth.

\section{Case 2}

A 48-year-old female reported to the department of Oral Medicine and Radiology with a complaint of multiple missing teeth in the upper and lower jaws and wanted replacement. Her past den- tal history revealed she had undergone extractions of retained deciduous teeth 25 years before.Her past medical history and family history were non-contributory.

On general examination the patient was well-oriented, moderately built and short in stature. On physical examination when she was asked to bring her shoulders forward, she was able to approximate both the shoulders anteriorly demonstrating the hypermobility of the joint (Figure IVa). On extraoral examination she had frontal bossing,hypertelorism with depressed nasal bridge (Figure IVb). Intraoral examination revealed multiple missing teeth,multiple decayed over-retained deciduous teeth with multiple unerupted permanent teeth (Figure Va\&Vb). Based on the clinical and intraoral features a provisional diagnosis of cleidocranial dysplasia was given.

Radiographic investigations including panoramicimaging,posterioanterior skull view and posterio-anterior chest view was advised for further evaluation. Panoramic image (Figure VIa) revealed the presence of a total 30 teeth including multiple missing, decayed over-retained deciduous teeth,multiple impacted permanent and supernumerary teeth distributed along the entire region of maxillary and mandibular alveolar bone.Posterio-anterior skull view (Figure VIb) revealed brachycephaly,presence of wormian bones,open fontanelles, thickened calvarium and poorly developed sinuses. The posterio-anterior view of the chest (Figure VIc) revealed bell shaped rib cage and complete absence of the clavicle on both the sides.

Based on the clinical,extraoral,intraoral and radiographic features a final diagnosis of cleidocranial dysplasia was given. The patient is currently being treated by a team comprising of oral and maxillofacial surgeon and prosthodontist, planned for surgical removal of impacted teeth and replacement of missing teeth.

\section{Discussion}

Cleidocranial dysostosis(CCD) is a rare genetic syndrome with autosomal dominant inheritance.CCD is usually caused by haploinsufficiency in the RUNX2 (runt related transcription factor 2) gene located on the short arm of chromosome 6 which has an important role in osteoblasts differentiation and maturation of chondrocytes [21-23]. This syndrome can be identified during prenatal ultrasonography but sometimes it is detected only after birth due to cranial deficiencies or presence of any not related medical pathologies or cranial deficiencies [24].

For a definitive diagnosis of CCD the pathognomonic triad of multiple impacted supernumerary teeth,partial or complete ab-

Figure 1. Ia showing approximation of shoulders, IIb \& IIc showing extra-oral features of frontal bossing, hypertelorism, depressed nasal bridge.

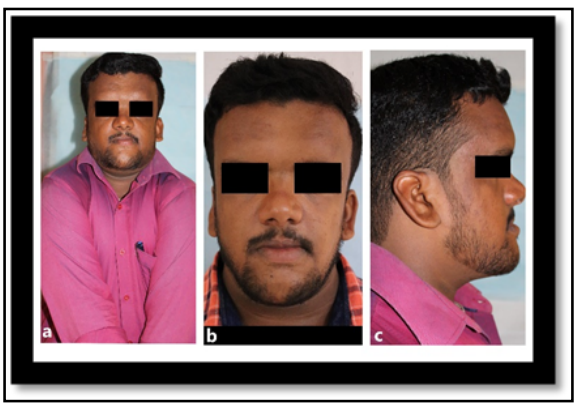


Figure 2. IIa showing maxillary arch showing missing permanent teeth in the anterior region and palate appearing narrow and constricted and figure IIb showing mandibular arch.

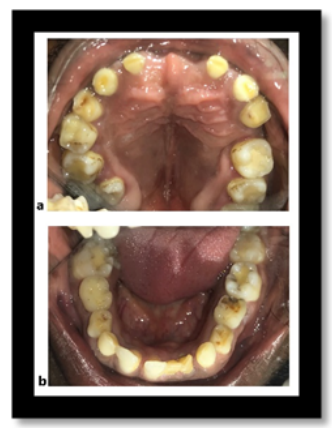

Figure 3. IIIa shows panoramic image showing a total of 63 teeth with multiple retained deciduous teeth, multiple impacted and supernumerary teeth in the maxillary sinus region, cuspid, bicuspid and tricuspid region. Figure IIIb showing PA view of the skull showing brachycephaly, open fontanelles, multiple wormian bones and poorly developed sinuses. Figure

IIIc PA view of the chest showing absence of clavicles bilaterally (white circles).

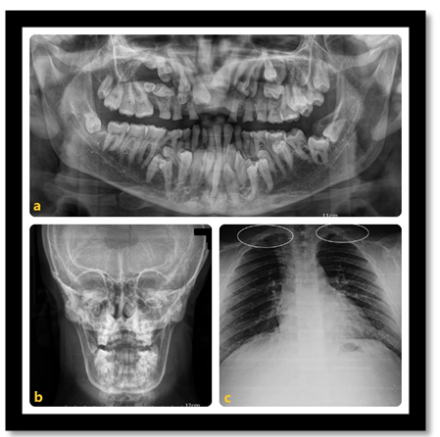

Figure 4. IVa showing approximation of shoulders, IVb showing extra-oral features of frontal bossing, hypertelorism, depressed nasal bridge.

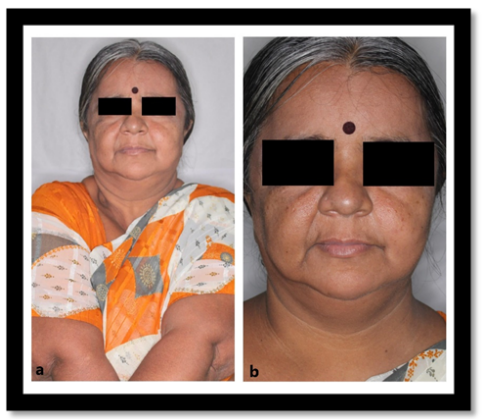

Figure 5. Va showing maxillary arch showing multiple missing and decayed teeth. Palate appearing narrow and constricted figure $\mathrm{Vb}$ showing mandibular arch.

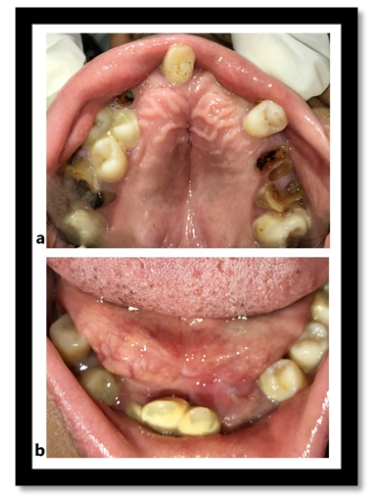

sence of clavicles and presence of open fontanelles \& cranial sutures must be present [25]. The genetic disturbances in the osteoblast differentiation results in abnormal dentition with overretained primary dentition,multiple impacted supernumerary and permanent teeth.
The clavicle is the first bone to undergo ossification and exhibits many deformities ranging from various degrees of hypoplasia to complete absence of clavicles. When the clavicles are completely absent which occurs in 10 percent of cases with cleidocranial dysplasia it results in hypermobile and drooping shoulders. 
Figure 6. VIa showing panoramic image showing a total of 30 teeth with multiple missing, over-retained decayed teeth, impacted permanent and supernumerary teeth. Figure VIIb showing PA view of the skull showing brachycephaly, open fontanelles, multiple wormian bones and poorly developed sinuses. Figure VIIc showingPA view of the chest showing absence of clavicles bilaterally (white colored cirlces).

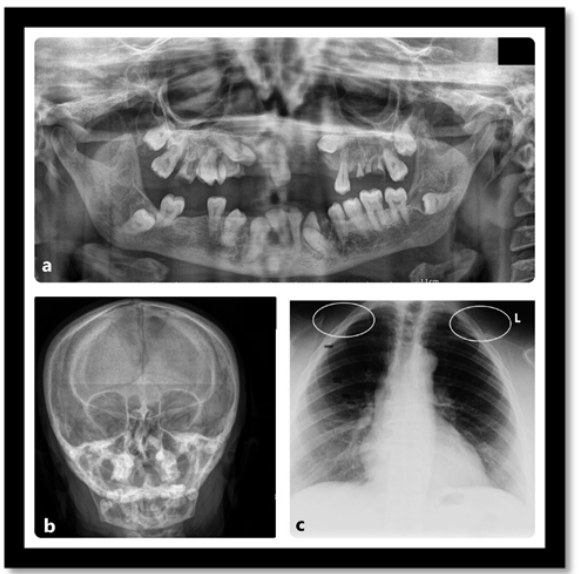

Pycnodysostosis also known as Marteau lamy syndrome exhibits clinical features similar to cleidocranial dysplasia, but it can be differentiated by presence of dwarfism. The affected patients have dense and fragile bones.Mandibulo-acral dysplasia (MAD) is a rare genetic disorder, characterized by short stature, delayed closure of cranial sutures, mandibular hypoplasia and dysplastic clavicles. The scalp hair becomes sparse by the third decade and some patients may develop alopecia.Micrognathia results from osteolysis of the body and ramus of the mandible.Crowding of teeth can be seen and early loss of tooth due to hypoplastic roots may occur.

Dental management of patients with CCD can be challenging. The fundamental treatment goal is to establish an aesthetic appearance and functional occlusion. The treatment plan depends on the chronological and dental age of the patient.The timing of the diagnosis is not only important in deciding an appropriate treatment plan but also in obtaining a successful result. The principles of treatment are focused on surgical intervention,orthodontic correction of malocclusion and prosthodontic rehabilitation [26, 27]. Dental management requires an interdisciplinary approach involving orthodontics, maxillofacial surgeon and prosthodontists.Every child born to an individual with CCD has a chance of inheriting the mutation. Hence it would be appropriate to provide genetic counselling to young patients who are affected [28-30].

\section{Conclusion}

The present case report highlights the need for awareness among dentists about CCD syndrome. When CCD is diagnosed in the early stages of life, a permanent dentition with proper functional occlusion, as well as an aesthetically satisfying facial appearance,motivation and psychological supportfor the patients and their family members, may be achieved by interdisciplinary team approach.

\section{Acknowledgement}

The authors would like to thank the college management for extending their support to our research.

\section{References}

[1]. McNamara CM, O'Riordan BC, Blake M, Sandy JR. Cleidocranial dysplasia: radiological appearances on dental panoramic radiography. Dentomaxillofac Radiol. 1999 Mar;28(2):89-97. Pubmed PMID: 10522197.

[2]. Zhang YW, Yasui N, Ito K, Huang G, Fujii M, Hanai J, et al. A RUNX2/ PEBP2alpha A/CBFA1 mutation displaying impaired transactivation and Smad interaction in cleidocranial dysplasia. Proc Natl Acad Sci U S A. 2000 Sep 12;97(19):10549-54. Pubmed PMID: 10962029.

[3]. Garg RK, Agrawal P. Clinical spectrum of cleidocranial dysplasia: a case report. Cases J. 2008 Dec 8;1(1):377. Pubmed PMID: 19063717.

[4]. Dard M. Histology of alveolar bone and primary tooth roots in a case of cleidocranial dysplasia. Bull Group Int Rech Sci Stomatol Odontol. 1993 Jul-Sep;36(3-4):101-7. Pubmed PMID: 8219688.

[5]. Brueton LA, Reeve A, Ellis R, Husband P, Thompson EM, Kingston HM. Apparent cleidocranial dysplasia associated with abnormalities of $8 \mathrm{q} 22$ in three individuals. Am J Med Genet. 1992 Jun 1;43(3):612-8. Pubmed PMID: 1605259.

[6]. The classic: Marie, P., and Sainton P.: Sur la dysostose cleido-cranienne herediataire, Rev. neurol. 6:835, 1898. On hereditary cleido-cranial dysostosis. Clin Orthop Relat Res. 1968 May-Jun;58:5-7. Pubmed PMID: 4875295.

[7]. Golan I, Baumert U, Hrala BP, Müssig D. Dentomaxillofacial variability of cleidocranial dysplasia: clinicoradiological presentation and systematic review. Dentomaxillofac Radiol. 2003 Nov;32(6):347-54. Pubmed PMID: 15070835.

[8]. KALLIALA E, TASKINEN PJ. Cleidocranial dysostosis. Report of six typical cases and one atypical case. Oral Surg Oral Med Oral Pathol. 1962 Jul;15:808-22. Pubmed PMID: 14453327.

[9]. De Nguyen T, Turcotte JY. La dysplasie cléidocrânienne: mise à jour et présentation d'un cas [Cleidocranial dysplasia: review of the literature and presentation of a case]. J Can Dent Assoc. 1994 Dec;60(12):1073-8. French. Pubmed PMID: 7842373.I

[10]. Roberts T, Stephen L, Beighton P. Cleidocranial dysplasia: a review of the dental, historical, and practical implications with an overview of the South African experience. Oral Surg Oral Med Oral Pathol Oral Radiol. 2013 Jan;115(1):46-55. Pubmed PMID: 23102800.

[11]. Yeom HG, Park WJ, Choi EJ, Kang KH, Lee BD. Case series of cleidocranial dysplasia: Radiographic follow-up study of delayed eruption of impacted permanent teeth. Imaging Sci Dent. 2019 Dec;49(4):307-315. Pubmed PMID: 31915617

[12]. Lotlikar PP, Creanga AG, Singer SR. Clinical and radiological findings in a severe case of cleidocranial dysplasia. BMJ Case Rep. 2018 Nov 12;2018:bcr2018226671. Pubmed PMID: 30420564.

[13]. Bufalino A, Paranaíba LM, Gouvêa AF, Gueiros LA, Martelli-Júnior H, Junior JJ, et al. Cleidocranial dysplasia: oral features and genetic analysis of 11 patients. Oral Dis. 2012 Mar;18(2):184-90. Pubmed PMID: 22023169.

[14]. Xuan D, Li S, Zhang X, Hu F, Lin L, Wang C, et al. Mutations in the RUNX2 gene in Chinese patients with cleidocranial dysplasia. Ann Clin Lab Sci. 2008 Winter;38(1):15-24. Pubmed PMID: 18316777.

[15]. Suda N, Hamada T, Hattori M, Torii C, Kosaki K, Moriyama K. Diversity of supernumerary tooth formation in siblings with cleidocranial dysplasia having identical mutation in RUNX2 : possible involvement of non-genetic 
or epigenetic regulation. Orthod Craniofac Res. 2007 Nov;10(4):222-5. Pubmed PMID: 17973689

[16]. Hemalatha R, Balasubramaniam MR. Cleidocranial dysplasia: a case report. Journal of Indian Society of Pedodontics and Preventive Dentistry. 2008 Jan 1;26(1):40.

[17]. González López BS, Ortiz Solalinde C, Kubodera Ito T, Lara Carrillo E, Ortiz Solalinde E. Cleido cranial dysplasia: report of a family. J Oral Sci. 2004 Dec;46(4):259-66. Pubmed PMID: 15901072.

[18]. Zheng Q, Sebald E, Zhou G, Chen Y, Wilcox W, Lee B, et al. Dysregulation of chondrogenesis in human cleidocranial dysplasia. Am J Hum Genet. 2005 Aug;77(2):305-12. Pubmed PMID: 15952089.

[19]. Counts AL, Rohrer MD, Prasad H, Bolen P. An assessment of root cementum in cleidocranial dysplasia. Angle Orthod. 2001 Aug;71(4):293-8. Pubmed PMID: 11510638.

[20]. Dysostosis WC. Histological and analytical studies of a tooth in a patient. No 2001; 2: 85-89.

[21]. Urzal V, Pinhão Ferreira A, Figueiredo A. Cleidocranial dysostosis-case report of a multidisciplinary approach. Revista de Odontologia da UNESP. 2013 Jun 4;40(1):53-7.

[22]. Smith N, Dong Y, Lian JB, Pratap J, Kingsley PD, van Wijnen AJ, et al. Overlapping expression of Runx1(Cbfa2) and Runx2(Cbfa1) transcription factors supports cooperative induction of skeletal development. J Cell Phys- iol. 2005 Apr;203(1):133-43. Pubmed PMID: 15389629.

[23]. Mundlos S. Cleidocranial dysplasia: clinical and molecular genetics. J Med Genet. 1999 Mar;36(3):177-82. Pubmed PMID: 10204840.

[24]. Currall V, Clancy R, Dimond D, Amirfeyz R, Kershaw C, Gargan M. Cleidocranial dysplasia. Current Orthopaedics. 2007 Apr 1;21(2):159-62.

[25]. Mehta DN, Vachhani RV, Patel MB. Cleidocranial dysplasia: a report of two cases. J Indian Soc Pedod Prev Dent. 2011 Jul-Sep;29(3):251-4. Pubmed PMID: 21985884.

[26]. Patel D, Patel N, Kwok J, Cobourne M. The staged approach to the treatment of patients with cleidocranial dysplasia: A case series. British Journal of Oral and Maxillofacial Surgery. 2017 Dec 1;55(10):e108-9.

[27]. Minocha P, Choudhary A, Sitaraman S. Cleidocranial dysplasia: A rare case report. Journal of Medical Sciences. 2017 May 1;37(3):110.

[28]. Shekhawat VS, Gulati YS. Cleidocranial dysplasia-A case report discussing the clinical and radiological manifestations. Journal of Marine Medical Society! Volume XX' Issue XX' Month. 2020:2.

[29]. Machol K, Mendoza-Londono R, Lee B. Cleidocranial dysplasia spectrum disorder.

[30]. Nayak P, Munde A, Deshpande A, Sawade R. Clinico-Radiographic spectrum of cleidocranial dysplasia: A case series. Indian Journal of Case Reports. 2020 Dec 16:606-11. 